\title{
How SNS Mediates EFL Adolescent Learners in Language Learning - From Learners' Perspectives
}

\author{
Sino Hui Fen Chen
}

\begin{abstract}
Abundant studies have shown that incorporating SNSs (social networking site) brings positive effects on language teaching and learning and enhances learners' learning spirit, interactions as a whole.

However, a large body of the research focused mainly on tertiary education. Adolescents' perspectives are often neglected. To fill the interstice, this mix-method research was conducted in 2012 to examine how a group on a SNS assists 9 EFL adolescent learners' English learning. The two research questions were as follows: 1) How does participation in a group on Facebook assist adolescent EFL learners in language learning? 2) How do adolescent EFL learners perceive the role of this group in language learning?

Data of the study were collected from, 1) on-line questionnaires, 2) group interviews, and 3) SNS postings and responses. The results obtained from the questionnaires show that $56 \%$ of the participants consider the existence of this group beneficial and $89 \%$ of the participants hold positive perspectives toward this group. The data obtained from the group interviews show that the participants perceive this group as a social bond and the extension of the classroom. Implications of this study were also discussed at the end of the paper.
\end{abstract}

Index Terms-SNS, Facebook, adolescent, EFL, language learning, learners' perspectives.

\section{INTRODUCTION}

To begin with, Jones \& Hafner (2012) [1] claimed that, "The tools that we use to mediate between ourselves and the world can be thought of as extensions of us. The way computers and the Internet extend our capabilities goes far beyond the things like memory and cognition." High exposure to the Internet and communication technology has become part of daily lives for young generation, which is also called "Net Generation" by Oblinger \& Oblinger (2005) [2]. Blattner \& Fiori (2009) [3] also emphasized the importance of meeting the connectivity demands made by today's "Digital Natives". The Net Generations, and the Digital Natives likewise, tend to be more positive an adventurous toward learning actively on the Internet. The mediation between themselves and the internet; accordingly, has greatly influenced on every aspect of their lives, including language education.

Technology and the Internet also revolutionize language learning and teaching all over the world. Blattner \& Fiori (2009) [3] argued that, "Technological innovations that underlie these changes cannot be ignored. Educators need to adapt their pedagogical posture to incorporate useful and

Manuscript received August 1, 2014; revised October 16, 2014.

Sino Hui Fen Chen is with the National Cheng-Chi University, Taipei, Taiwan, R.O.C. (e-mail: sinowhateveritis@yahoo.com.tw). versatile e-tools that will enhance the quality of their classrooms, guide learners to utilizing various e-tools for academic purposes, create a dynamic learning environment, and promote critical thinking, authentic second language (L2) learning opportunities and deeper connections with the culture of the native L2 speakers." With the burgeoning development of current online technology, the Net Generations and the Digital Natives both engage on the Internet to a great extent to fulfill their needs in education. Throne, black, \& Sykes (2009) [4] claimed that, "Communication, computer-mediated communication (CMC) has become a high-stakes, high-frequency context for all manner of professional, academic, and social activity."

Among all the SNSs (Social Networking Sites), Facebook plays a rather significant role in language teaching and learning. According to Facebook Annual Report [5], there were 1.2 billion MAUs (monthly active users) every month. Moreover, there were 945 million mobile monthly active users (MAUs) in December 2013. The top priorities of Facebook enable the users to "1) connect and share with their friends, 2) discover and learn, 3) express themselves, and 4) stay connected everywhere." With these priorities, all the Net Generations and Digital Natives are able to connect, share, discover, and communicate with each other either on their mobile devices or via their desk-top computers. These features have also established a monolithic platform for L2 language teaching and learning. Blattner \& Lomicka (2012) [6] stated that, "Facebook offers a wide array of technological affordances supporting a diverse range of interests and practices which integrate several modes of Computer Mediated Communication (CMC) such as self-presentation, and one-to-one or one-to-many written exchanges." As for language learning, Kabilan, Ahmad, \& Abidin (2010) [7] claimed that the learners are able to learn the target language, build their confidence, and increase their motivation when engaging with other learners on Facebook.

Language learning is constructed in social interactions. Being recognized and identified in a group which the target language is spoken, learners engage in language learning and strive to reach their language competence. Firth \& Wagner (1997) [8] asserted that, "Learning is an inseparable part of ongoing activities and therefore situated in social practice and social interaction." Moreover, Firth \& Wagner also stated that, "We are concerned to uncover learning as a ubiquitous social activity, as an interactional phenomenon that transcends contexts while being context dependent, specifically in relation to encounters where an L2 is in use. Learning is certainly a process that takes place in the micro moments of social interaction in communities of practice." Jones \& Hafner (2012) [1] further claimed that, "A more profound affordance that has come from social networking is 
that, it has given internet users the ability to create the connections between the content based on social relationships" (p. 144). L2 socialization acknowledges that additional languages, codes, or varieties are also learned through socialization [9]. Additionally, Duff (2007) described L2 socialization as the processes involved when L2 learners "seek competence in the language and, typically, membership and the ability to participate in the practices of communities in which that language is spoken."

In recent years, a great deal of research related to language learning on Facebook has been done and revealed how ubiquitous SNSs place unprecedented importance on language teaching. Garrison (2004) [10] asserted that a sense of community on Facebook is essential to sustain a meaningful educational experience. The adoption of Facebook also arouses learners' socio-pragmatic awareness. Moreover, abundant studies have shown that incorporating Facebook in language teaching brings positive effects on learners' learning. [3], [6], [11]. Learning with a sense of group on Facebook enhances learners' learning spirit, interactions as a whole [12].

However, a large body of the research has been done and focused mainly on either EFL college students or ESL college students. EFL Adolescent learners' perspectives are often neglected. On top of that, most of the groups on Facebook were established with the view to satisfying either learner's academic language performance or shared learning interests. Namely, most groups on Facebook in previous research were established for meeting one single purpose -it may be either for grade-oriented or interest-oriented. Very little attention has been paid to a group established to meet the dual purposes for learners, which are learners' academic needs and interest needs. Meeting the dual purposes here refers to establishing a group with the view to improving learners' academic language performance and foster learners' learning interests via having social interactions with other learners in the group. With the hope of filling this interstice in the previous research, this study aimed at EFL adolescences' perceptions of language learning in a group on Facebook, where learners' dual needs are met.

Lantolf and Thorne (2007) [13] claimed that learner's participation in a community is essential for effective language learning. Thorne , Black, \& Sykes, (2009) [4] further argued that, "As with all the pedagogical choices in L2 education, desired learning outcomes must align with reasonable expectations of the kinds of linguistic and interactional expertise that may be developed through participation within a particular activity, speech community, and/or modality." Based on Lantolf and Throne's (2007) [13] L2 social cultural theory, the purpose of this mix-method study was to examine how participation in this group on Facebook mediated EFL adolescent learners in their language learning with the framework built on the theory of L2 socialization. The two research questions of present study were:

1) How does participation in a group on Facebook assist adolescent EFL learners in language learning?

2) How do adolescent EFL learners perceive the role of this group in language learning?

To answer these two research questions, data of the study were also collected from, 1) on-line questionnaires, 2) group interviews, and 3) SNS postings and responses in a group on Facebook named "Krino". The results of this study show that the participants take this social networking site as a "social bonding" which is also the "completion or extension of the course". The majority of the participants hold not only a positive attitude towards incorporating this SNS in their language learning but also anticipations towards more development of this SNS in the future. The participants' perceptions also provide valuable pedagogical implications in language teaching. Three directions for future study were also given.

\section{LITERATURE REVIEW}

To learn a language, learners have to engage themselves in socially constructed settings so that they can practice the target language and communicative with each other in meaningful context. Black and Thorne (2007) [14] stated that the "Opportunity to interact primarily with peers and within a peer-centered communication environment affords opportunities to perform identities not traditionally associated with those of 'student' in instructed institutional contexts." [4], "The use of L2 and multiple languages for engaging in interpersonally meaningful communication and identity construction serves goals that enhance, and potentially extend beyond, the practices and standardized forms of knowledge associated with institutional educational settings. This includes engaging in multiple forms of authentic communication, developing a sense of accomplishment as language users, affiliating with the target language, and learning to navigate and develop supportive social networks." Furthermore, Norton \& Toohey [15] (2002) proposed that language is both a linguistic system of signs and a complex social practice. Black, Sykes, \& Thorne (2009) [4] further argued that, "As with all the pedagogical choices in L2 education, desired learning outcomes must align with reasonable expectations of the kinds of linguistic and interactional expertise that may be developed through participation within a particular activity, speech community, and/or modality."

With the advent of SNSs on the Internet, the ways of language teaching learning have been renovated and revolutionized. Participating in SNSs on the Internet has become a part of language teaching curriculum. Teachers and learners utilize SNSs to meet outside campus, hand in assignment, give feedback, and compensate whatever real classrooms are lacking of. Blattner and Fiori (2009) [3] stated the importance on the Group application on Facebook, which was "an aspect of language acquisition that is often omitted in textbooks." Blattner and Fiori further stated that, "It is imperative that second language (L2) classes plug into the network, and the student body that operates it, to capitalize on the social and academic opportunities that high-tech learning has to offer" (p. 18).Similarly, Blattner\& Lomicka (2012) [6] stated that, "Students have to engage in authentic and meaningful exchanges, which are essential in order to develop communicative competence, and this cannot be achieved by exclusively focusing on learners' grammatical and lexical knowledge." To engage language learners in 
authentic and meaningful communication, a SNS such as Facebook provides learners a platform to culturally and socially communicate with each other outside the classroom on a daily basis.

Apart from providing learners a communication platform, Facebook makes language learning easier and its outcome more satisfactory with its unique features. Schwartz (2009) [16] argued that one of the major functions of Facebook is that it blocks certain viewers from seeing certain information. This provides the chances for users to tailor their own settings. When taken this feature into language learning, this feature enables language teachers to select and design certain tailor-made materials to meet learners' specific needs. Moreover, Facebook not only undoubtedly builds up a sense of belong but also "offers constructive learning experiences with its features while maintaining privacy and safety with its unique features." Kabilan, Ahmad, \& Abidin (2010) [7] suggested that the students are able to increase their motivation and positive attitude toward language learning through the interactions on Facebook, whose features make language learning more digital, customized, and effective.

A considerable number of studies have revealed the advantages of adopting groups on Facebook in language learning. Blattner \& Lomicka (2012) [6] investigate using Facebook and students' responses in a language course. The participants were 24 young students aged between 18 and 21 . The purpose of adopting Facebook as mediation is to develop learners' linguistic competence and extend learning outside the classroom. The participants were firstly given nine topics separately and then told to respond to each of the topic in 50 words on Facebook. Data were collected via the implementation of a pre-survey and a post-survey. The results of the study reported that the learners liked the use of Facebook for two main reasons. One reason was facilitation of communication among students and faculty. The other was language cultural exchange. Blattner \& Lomicka (2012) [6] also claimed that, "The students discovered how Facebook can become a pedagogical tool in the context of foreign language classes and how they can exploit this resource outside of the classroom."

Additionally, a study done by Arthur, Sherman, Appel, \& Moore (2006) [17] examined that why young Australian young adopted interactive technologies like Facebook and MySpace. The participants' ages were between 16 and 24 . The results of the study revealed that applying SNS in language learning was the presence of self-identity, the immediacy, and interactivity. Furthermore, Mills (2011) [18] conducted a study to examine 17 college students whose online identities were transformed on a Francophone Facebook. In her study, it was found that learners' participation on Facebook "enhance a strong sense of ownership in the collective story and their characters' identity and relationships."

To sum up, the revolution and innovation of SNSs empower language teachers with more time and possibilities to engage learners in a socially and culturally constructed learning process. The participation in SNSs presents learners' identities, enhances learners' relationships with others, and facilitates learners' practice of the target language. According to Throne (2009) [4], "Language socialization proposes a model of language development that unites becoming a speaker of a language with participation in particular speech communities." With the unique features of SNSs and learners' synchronic online interactions, learners are able to construct their own viewpoints with other learners socially and effectively. In addition, the conventional forms of classroom are extended by engaging learners in SNSs through various posted links and learning resources. By so doing, learners' self-awareness, autonomy, motivation, and learning outcome are accordingly enhanced.

\section{Methodology}

This mix-method study aimed to examine how participation in a group on Facebook mediates EFL adolescent learners in language learning. Before the present study was conducted, the researcher had established a group named "Krino" on Facebook in spring, 2011. The group was served to provide 32 EFL learners a platform to interact socially for the purpose of English learning. The group consisted of one Taiwanese teacher, one foreign teacher, 15 senior high students and 17 college students. The average age among all the learners was 17.5. The members of the group attended a 3-hour English course taught by both teachers once a week. The goal of the English course was to underpin participants' solid learning foundation, foster their four skills in language learning, and facilitate participants' language competence so that they would be able to perform well on their coming language tests and college entrance test.

Lantolf and Thorne (2007) [13] claimed that learner's participation in a community is essential for effective language learning. This theory is served as the buttress of this mix-method study. This study was conducted in the spring of 2013. A total of nine members of the group voluntarily took part in this study to examine how these nine adolescent learners' participation in this SNS mediated their English learning and how they perceived the role of this SNS Participants' anticipations of the group in the future were also discussed. The two research questions of this study were:

3) How does participation in a group on Facebook assist adolescent EFL learners in language learning?

4) How do adolescent EFL learners perceive the role of this group in language learning?

The data of the study were also collected from 1) on-line questionnaires, which consist of five questions, 2) group interviews, and 3) SNS postings and responses. The online-questionnaire was firstly made to examine the nine participants' behaviors in this group on Facebook, Krino. The five questions in the on-line questionnaires were as follows, 1) How often do you check Facebook? 2) How long have you been a member of this group (Krino) on Facebook? 3) Under what circumstance do you visit this group on Facebook? 4) Do you think this group on Facebook helps you learn English? 5) How do you like this group on Facebook? Secondly, the researcher conducted group interviews with the participants in three groups to explore participants' deeper perceptions of this SNS. The three questions asked were as follows, 1) How do you perceive this group in your language learning? What role does it play? 2) How does this group assist you in your language learning? 3) What are your 
anticipations of this group in the future? The content of the interview was also coded and triangulated to enhance the reliability and validity of the study. Lastly, the data obtained in group interviews were cross-analyzed with the SNS postings and responses. The results of the present study will be revealed in the next section, which now we turn to.

\section{FINDINGS}

Based on the finding obtained from the questionnaires, it is noted that $56 \%$ of the participants check their Facebook several times a day (Table I). Whether or not being senior members or active users of this SNS, $89 \%$ of the participants visit this group as long as there are new postings. (Table II and Table III) Most importantly, 78\% of the participants consider this group beneficial to their English learning and $89 \%$ of the participants show their positive personal preferences towards this group on the social networking site (Table IV and Table V).

TABLE I: HOW OFTEN DO YOU CHECK FACEBOOK

\begin{tabular}{l|l|l}
\hline Options & NOP & Percentage \\
\hline Very rarely. & 1 & $11 \%$ \\
\hline Once or twice a day. & 3 & $33 \%$ \\
\hline Several times a day $\cdot$ & 5 & $56 \%$ \\
\hline Several times a week. & 0 & $0 \%$ \\
\hline Other. & 0 & $0 \%$ \\
\hline
\end{tabular}

NOP: Number of participants

TABLE II: How LONG HAVE You BEEN THE MEMBER OF THIS GROUP (KRINO) ON FACEBOOK

\begin{tabular}{l|l|l}
\hline Options & NOP & Percentage \\
\hline Less than 6 months. & 1 & $11 \%$ \\
\hline 6 months to 1 year. & 1 & $11 \%$ \\
\hline 1 year to 1.5 years. & 3 & $33 \%$ \\
\hline 1.5 years to 2 years. & 4 & $45 \%$ \\
\hline More than two years. & 0 & $0 \%$ \\
\hline
\end{tabular}

TABLE III: UNDER WHAT CIRCUMSTANCE DO YOU VISIT THIS GROUP ON

\begin{tabular}{|c|c|c|}
\hline \multicolumn{3}{|l|}{ FACEBOOK } \\
\hline Options & NOP & Percentage \\
\hline I rarely check it. & 0 & $0 \%$ \\
\hline I often check it. & 1 & $11 \%$ \\
\hline I check it when my name is tagged. & 0 & $0 \%$ \\
\hline I check only when something new is posted. & 8 & $89 \%$ \\
\hline $\begin{array}{l}\text { I check it whenever I log on my Facebook } \\
\text { account. }\end{array}$ & 0 & $0 \%$ \\
\hline
\end{tabular}

TABLE IV: Do YOU THINK THIS GROUP ON FACEBOOK HELPS YOU LEARN ENGLISH

\begin{tabular}{l|l|l}
\hline Options & NOP & Percentage \\
\hline Strongly disagree. & 0 & $0 \%$ \\
\hline Disagree. & 0 & $0 \%$ \\
\hline OK. & 2 & $22 \%$ \\
\hline Agree. & 5 & $56 \%$ \\
\hline Strongly agree. & 2 & $22 \%$ \\
\hline
\end{tabular}

\begin{tabular}{l|l|l}
\multicolumn{2}{c}{ TABLE V: HOW DO YOU LIKE THIS GROUP ON FACEBOOK } \\
\hline Options & NOP & Percentage \\
\hline I strongly dislike it. & 0 & $0 \%$ \\
\hline I don't like it. & 0 & $0 \%$ \\
\hline It is not so bad. & 0 & $0 \%$ \\
\hline I like it. & 8 & $89 \%$ \\
\hline I like it very much. & 8 & $11 \%$ \\
\hline
\end{tabular}

Acknowledging the participants' frequency of participation in this SNS, the researcher then conducted the group interviews to further understand the participants' deeper perceptions of this SNS. After the interviews, valuable data were obtained and analyzed. The results of interview will be discussed in the following three aspects, which are 1) shared repertoire, 2) pedagogical affordance, and 3) future anticipations.

\section{A. Shared Repertoire}

During the group interviews, one participant said that, "Sometimes there are photos about our interesting class or activities". The other participant of this SNS mentioned that, "This group is just like a video recording which recorded all the things happened in this class. Whenever I visit this group, all the postings there remind me of our beautiful memories." One of the participants said that, "I wouldn't say this group is necessary, but it is convenient when the members of the group have something interesting and educational to share."

The researcher then browsed a great numbers of postings in this group and found some postings which elucidated how the participants took this SNS as a shared repertoire. The participants often checked the posted pictures pertaining to in-class activities and pressed the "like" button. One of the participants once gave a response like, "I looked so silly in this picture." This response showed the participants did not check photos or postings passively in this SNS; rather, they intended to express their individual opinions in this community. Additionally, one of the participants posted the information about his drama performance in another posting, with the intention to invite other participants to his showcase. Moreover, one time the researcher posted a link of a song and write a short message to encourage the participants who were about to take college entrance test then. This posting was one of the most viewed postings and received 15 messages responded by the participants and the researcher. 
Simply put, the participants built up their own identities and were willing to express themselves freely in this group with the sense of belonging to this community. Namely, this "social bonding" engaged learners in an authentic and socio-linguistic context which facilitated the participants' language learning. Through communicating with each other socially and being identified in this shared community, participants considered this group on Facebook a shared repertoire.

\section{B. Pedagogical Affordance}

During the group interviews, one participant expressed how this group assists him in language learning. "It helps me with the writing skills the most. When I was confused, I would check the information which my teacher posted in this group. Then, I can figure out what mistakes I've made." addressed by one of the participants. Another participant mentioned that, "If many students are absent in class, they are able to catch up with the schedule and the multimedia information because teachers always posts things like this." Similarly, two participants considered that, "This group on Facebook is another media or access to learn English or to absorb knowledge" so that they were able to "broaden their horizons by learning in this group", said by one of the participants. One participant of the group mentioned that, "It's like an information platform; you can get the latest international news, the English-learning websites and also some inspiring articles." One participant also said that, "Teacher sometimes posts a TED video on it; it's really inspiring and useful. And most importantly, it improves my English." Furthermore, "In class, the time and the access to the Internet is somewhat limited," one participant said that, "Not all of the videos and music can be played. We can visit this group after class if anyone wants to show something else here. So I consider this group as an information platform." Additionally, one of the participants said that, "I believe language learning isn't something we only do in class, but something we do in daily life. People who learn a foreign language should make the language become a part of their life. That's how this group assists us in our language learning."

Scrolling down pages of postings on the screen, the researchers found quite a lot of previous postings and responses which accounted for how the pedagogical affordances of Facebook facilitate the participants' English learning. Interestingly, all the links pertaining to writing skills received the least responses by the participants; however, one of the participants did claim that he thought the writing resources benefited him the most. This interesting finding reveals that learners' learning process is more than what it looks like. Even the participants simply hit the "like" button, it did not mean learners' learning could be neglected or underestimated.

In one posting about a piece of TED talk, one of the participants posted, "It also has app for Android phones." This response clearly shows the participant's interests were arisen and motivation developed. One time, the researcher had an on-line survey on music preferences, which was served as a preview for a unit in the textbook. The content of that unit claimed that people's preferences in music represent their personalities. The participants finished the survey first then learned how the descriptions of personalities vary for people who have different music preferences. At that time, one of the participants were preparing for his paper work for college enrollment. He finished the online survey, read the description, and then posted, "Now I know what to write about myself in my biography of my resume." Based on the above postings and responses, it is noted that the participants were able to fetch various channels to obtain knowledge and learn English by utilizing this SNS.

Based on the aforementioned content of interview and what was observed from the postings and responses, it can be seen that this group is a forum for the participants to reinforce what they have learned inside and outside the conventional classroom. This forum also provides the participants with more useful links and learning resources, regardless of the fact that it is hard to speculate how the participants perceived the links and resources since the only observable artifact was how many times the "like" button was pressed. Surprisingly, during the interview, the researcher found out how certain postings actually benefited the participants even though there were very rare or sometimes none responses to the postings. From the interviews and numerous postings and responses, it can be seen that the participants showed their enthusiasm towards the learning resources posted by the researcher. This group on Facebook was perceived as "the extension or completion of the course" which provided the participants with more channels to obtain knowledge. Most importantly, according to the last interview, the participant's motivation was improved and learner's autonomy was also raised via participating in this SNS.

\section{Future Anticipations}

When asked about the anticipations of this group, several of the participants thought this group functioned well and it would be nice to "make the group stay the way it is now." Two participants expressed their intentions to see "more useful posting such as idiom learning or music links." The participants also expected to see more social interactions in this group. Another participant said, "I hope that it could be more social, I mean people could chat and discuss more here. We can share more different thoughts and opinions about news, music, grammar, pop culture... etc." One participant suggested holding a class reunion, which took place after the interview.

When the researcher browsed the abundant postings and responses in this group, it was found that one time, the researcher once posted a talk in the TED talk which was pertaining to delivering public speaking. In that posting, a total of 10 responses were made between the researcher and the participants. One participant posted that, "I think she's beautiful...yes, and I also like the way she talks....I am looking forward to watching more good looking girls or guys. Hahaha." Based on the above anticipations held by the participants, it is clear that learners expect to see more diverse links of learning resources. Thus, it is believed the participants would like to engage themselves in more social interactions with other members in this group and see more educational learning resources in the future continuously.

To conclude, the participants connect themselves with 
others in this group, which is considered the "shared repertoire". Moreover, the participants take this social networking site as a social bonding as well as the completion or extension of the course, which is the "pedagogical affordance" of this SNS. The unique features of Facebook allow learners engage in a social context and enable the instructor to provide the participants with more knowledge forms and teaching resources, which is essential for contemporary language learning. During the dynamic processes taken in this group on Facebook, more self-awareness is arisen and the participants' motivation is increased. The majority of the participants hold not only a positive attitude towards incorporating this SNS in their language learning but also anticipations towards more development of this SNS in the future.

\section{COnClusion And Discussions}

Firth and Wagner (1997) [8] once stated that language learning is a process accumulated by on-going social practice and social interaction. Lantolf and Throne (2007) [13] placed the importance on participating in a community which the target language is spoken when it comes to language learning. Furthermore, Duff (2007) [9] described L2 socialization as the processes which learners "seek competence in the language and, typically, membership and the ability to participate in the practices of communities in which that language is spoken." Moreover, SNSs in language learning are of great benefit for language teachers to obtain new insights into the relationship between the new digital literacy and the deconstruction of traditional language classroom [19] Among all the SNSs, Facebook is considered a valuable tool in language teaching. It promotes a community for learners and it often positively impacts learners' learning and motivation. All of these have made Facebook a strong predictor of successful language learning.

The purpose of this study was to explore how the participation in SNSs mediates EFL adolescent learners in their English learning and how learners perceived the role of this group on Facebook in their English learning. This group engaged the participants socially and linguistically, which is of importance for EFL learners' effective learning. In this SNS, the participants had the chance to find their identities and engage themselves in authentic and meaningful communication in the target language. The role of this group is perceived as a "social bonding" and "the completion or extension" of the course by the participants. With the salient and powerful affordances of Facebook, the participants are benefited through learning English from various resources and knowledge forms which are no longer constrained by the limitations of space and time. This result also coincides with the "increasing autonomy" proposed by McBride (2009) [20]. However, the drawn conclusions of this study also lead us to reexamine the following three aspects in terms of the correlation intertwined among SNS, language teaching, and learning.

Firstly, ethnographic studies pertaining to heterogeneous users of SNSs are encouraged. With the evolutionary and innovative features on numerous SNSs, along with the increasing young users on Facebook, learners at different ages and with different English proficiency are able to expose themselves in SNSs. Thus, heterogeneous language learners' perspectives towards SNSs and their learning outcome are worth more attention in the future. Secondly, more quantitative studies in the future will shed more light on incorporating SNSs in language teaching. It is noted that the over-generalized "like" or "viewed" buttons on SNSs provide insufficient information of their users and viewers. For instance, in this present study, it had been surprisingly found out that certain postings actually benefited the participants even though there were only very few "likes", not to mention that sometimes there were not any responses to the postings. Therefore, the weight of future study on SNSs might be placed on viewers' actual view points and psychological status when participating in SNSs. Lastly, regardless of the fact that adopting SNSs has become a pervasive phenomenon, the lacking of effective pedagogies for incorporating SNSs in language teaching somehow mitigates the expected teaching efficacy and learning results. Adopting SNSs in language teaching might fall through or purely end up assignment relocation. Thus, teacher's training courses and the rule of thumb in adopting SNSs in language teaching are urged for language educators and practitioners in the near future.

To conclude, we now live in an exponential era, with the encompassing features of SNSs and the increasing number of their users, it is ineluctable for language teaches to reexamine the role of this ubiquitous tool and the impacts it brings on language teaching and learning. More ethnographic and quantitative research, along with rule of thumb in incorporating SNSs in language teaching will obviously be expected and required to accelerate new development of pedagogy paradigm on language teaching. By doing so, the adoption of SNSs would definitely expand language learning and teaching to a further and unlimited territory in the coming digital centuries.

\section{REFERENCES}

[1] R. H. Jones and C. A. Hafner, Understanding Digital Literacies-a Practical Introduction, Routledge, London and New York, 2012.

[2] D. G. Oblinger and J. L. Oblinger. (2005). Educating the Net Generation. [Online]. Available: http://net.educause.edu/ir/library/pdf/pub7101.pdf

[3] G. Blattner and M. Fiori, "Facebook in the language classroom promises and possibilities," Instructional Technology and Distance Learning (ITDL), 2009, vol. 6, no. 1, pp. 17-18.

[4] S. L. Throne, R. W. Black, and J. M. Sykes, "Second language use, socialization, and learning in internet interest communities and online games," The Modern Language Journal, vol. 93, pp. 802- 821, 2009.

[5] Facebook Annual Report. (2013). [Online]. Available: http://files.shareholder.com/downloads/AMDA-NJ5DZ/3136767913x 0x741493/EDBA9462-3E5E-4711-B0B4-1DFE9B541222/FB_AR_3 3501_FINAL.pdf

[6] G. Blattner and L. Lomicka, "Facebooking and the social generation: a new era of language learning," Alsic, 2012, vol. 15, no. 1, pp. 1-27.

[7] M. K. Kabilan, N. Ahmad, and M. J. Z. Abidin, "Facebook: an online environment for learning of English in institutions of higher education?" The Internet and Higher Education, vol. 13, no. 4, pp. 179-187, 2010.

[8] A. Firth and J. Wagner, "Second/foreign language: learning as a social accomplishment: elaborations on a reconceptualized SLA," The Modern Language Journal, vol. 91, pp. 800-819, 1997.

[9] P. Duff, "Second language socialization as sociocultural theory: insights and issues," Language Teaching, vol. 40, pp. 309-319, 2007. 
[10] D. R. Garrison, "Student role adjustment in online communities of inquiry: model and instrument validation," $J A L N$, vol. 8, no. 2, pp. 61-74, 2004.

[11] P. B. O'Sullivan, S. K. Hunt, and L. R. Lipper, "Mediated immediacy: a language of affiliation in a technological age," Journal of Language and Social Psychology, vol. 23, pp. 464-490, 2004.

[12] A. Kok, "Metamorphosis of the mind of online communities via e-learning," Instructional Technology and Distance Learning, 2008, vol. 5 , no. 10 , pp. $25-32$.

[13] J. P. Lantolf and S. L. Thorne, "Socialcultural theory and second language learning," in Theories in Second Language Acquisition: an Introduction, B. V. Patten and J. Williams eds., New York: Routledge, 2007.

[14] R. Black and S. L. Thorne, "Language and literacy development in computer-mediated contexts and communities," Annual Review of Applied Linguistics, vol. 27, pp. 133-160, 2007.

[15] B. Norton and K. Toohey, "Identity and language learning," in the Oxford Handbook of Applied Linguistics, R. B. Kaplan ed., Oxford: Oxford University Press, 2002, pp. 115-123.

[16] H. L. Schwartz. (2009). Facebook: The new classroom commons. The Chronicle Review. [Online]. Available: http://gradstudies.carlow.edu/pdf/schwartz-chronicle_9-28-09.pdf
[17] D. Arthur, C. Sherman, D. Appel, and L. Moore, "Why young consumers adopt interactive technologies: a valued-based approach," Young Consumers, vol. 7, no. 3, pp. 33-38, 2006.

[18] N. Mills, "Situated learning through social networking communities: the development of joint enterprise, mutual engagement, and a shared repertoire," Calico, vol. 28, no. 2, pp. 345-368, 2011.

[19] J. Lockard and M. Pegrum, Brave New classrooms: Democratic Education and the Internet, Peter Lang., 2007.

[20] K. McBride, "Social-networking sites in foreign language classes: opportunities for re-creation," Calico, vol. 8, pp. 35-58, 2009.

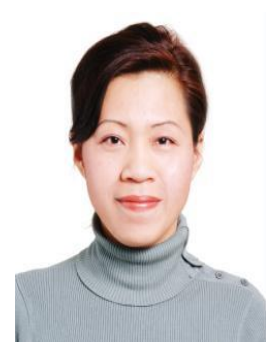

Sino Hui Fen Chen has been teaching English a language institutions, private tutoring and technology universities in Taiwan for more than 18 years. She is also capable of delivering teacher workshops and in-service teacher training. She has broad research interests in teacher development, teacher beliefs, SLA, testing, and writing. She is now pursuing her $\mathrm{PhD}$ program at the department of English at National Cheng-chi University in Taipei, Taiwan, R.O.C 